\title{
Caracterização hidrológica e suscetibilidade de risco à inundação nas bacias do município de Arroio do Padre/RS
}

A ocorrência de inúmeros eventos extremos relacionados ao clima no Brasil acarreta em perdas econômicas e socioambientais todos os anos, em especial os alagamentos e as inundações. A ocorrência e a magnitude desses danos dependem das vulnerabilidades associadas às condições sociais, econômicas, políticas, ambientais, climáticas, geográficas e sanitárias do território. Devido aos sucessivos episódios de enxurradas no município de Arroio do Padre/RS, o objetivo do presente estudo foi descrever as consequências desses eventos, caracterizar o sistema hidrológico local, bem como analisar a suscetibilidade de ocorrência enxurradas no município. A metodologia escolhida para análise espacial foi feita através de Sistema de Informação Geográfica (SIG) pelo Software Livre Quantum Gis Wien versão 2.8.1. Foi empregado o uso de ferramentas de geoprocessamento, para obtenção dos limites das bacias hidrográficas. Para avaliação das características hidrológicas, foram calculadas as características morfométricas a fim de observar se as bacias hidrográficas geradas são sucessíveis a inundações, através dos avaliação das características hidrológicas, foram calculadas as características morfométricas a fim de observar se as bacias hidrográficas geradas são sucessíveis a inundações, através dos o mapa de risco de inundação para o munícipio utilizando SIG em conjunto com o método de Análise Hierárquica de Pesos (AHP). Verificou-se que a área urbana de Arroio do Padre apresenta um número reduzido de áreas propensas tanto para inundações quanto para alagamentos, no entanto, a situação não se repete na zona rural do município. Pela análise do Ic constatou-se que todas as bacias hidrográficas que englobam o município apresentam tendência a cheias, o que foi confirmado pelo mapa de risco a inundação gerado para a área de estudo. Portanto, verificou-se que o município de Arroio do Padre apresenta grande tendência a ter inundações bruscas. Ressalta-se a importância da realização de diagnósticos utilizando sistemas de informação geográfica para a realização de estudos de bacias, pois estes se apresentam como ferramentas de otimização e planejamento ambiental, que potencializam a gestão das políticas públicas na área.

\section{Hydrological characterization and susceptibility of risk to flood in the watershed of the city of Arroio do Padre/RS}

\begin{abstract}
The occurrence of numerous extreme events related to the climate in Brazil leads to economic and socio-environmental losses every year, especially floods. The occurrence and magnitude of such damage depends on the vulnerabilities associated with the territory's social, economic, political, environmental, climatic, geographic and health conditions. Due to the successive episodes of floods in the city of Arroio do Padre/RS, the objective of the present study was to analyze the consequences of these events, the characteristics of the hydrological system, as well as the susceptibility of occurrences of floods in this city. The methodology chosen for spatial analysis was made through GIS (Geographic Information System) by the Free Software Quantum Gis Wien version 2.8.1, the use of geoprocessing tools was used to obtain the limits of the watersheds. In order to evaluate the hydrological characteristics, the morphometric characteristics were calculated in order to observe if the watersheds generated are successive to floods, through the parameters such as Coefficient of Compaction (Kc), Index of Conformation (Ic) and Time of Concentration (TC). In order to compare the results obtained by the morphometric analysis, a flood risk map was generated for the city using SIG in conjunction with the Hierarchical Analysis of Weights (AHP) method. It was noticed that the urban area of Arroio do Padre presents a reduced number of areas prone to both flooding and flooding however, the situation is not repeted in the rural a situation is An refor ens usin geographic information systems to carry out watershed studies, since these are presented as optimization tools and environmental planning, which enhance the management of public policies in the area.
\end{abstract}

Keywords: Geographic Information System; Watershed; Management of basins; Public administration; Water resources.

Topic: Planejamento, Gestão e Políticas Públicas Ambientais

Reviewed anonymously in the process of blind peer.

Mélory Maria Fernandes de Araujo Universidade Federal de Pelotas, Brasil http://lattes.cnpq.br/8882512834751864 http://orcid.org/0000-0002-8552-8407 mmfa.eh@gmail.com

Ana Luiza Bertani Dall'Agnol (iD

Universidade Federal de Pelotas, Brasil http://orcid.org/0000-0002-8620-0390 analuizabda@gmail.com

Diuliana Leandro (ic)

Universidade Federal de Pelotas, Brasil http://lattes.cnpq.br/3076528365846421

http://orcid.org/0000-0002-8092-5550 diuliana.leandro@gmail.com
Received: 02/12/2018 Approved: 26/01/2019

\author{
Andréa Souza Castro \\ Universidade Federal de Pelotas, Brasil \\ http://lattes.cnpq.br/4328855884811171 \\ http://orcid.org/0000-0003-1989-684X \\ andreascastro@gmail.com \\ Maurizio Silveira Quadro ib \\ Universidade Federal de Pelotas, Brasil \\ http://lattes.cnpq.br/1749935262841216 \\ http://orcid.org/0000-0001-8236-7479 \\ mausq@hotmail.com \\ Gustavo Farias Lima \\ Universidade Federal de Pelotas, Brasil \\ http://lattes.cnpq.br/4704938849588960 \\ limagustavo416@gmail.com
}

Referencing this:

ARAUJO, M. M. F.; DALL'AGNOL, A. L. B.; LEANDRO, D.; CASTRO, A. S.; QUADRO, M. S.; LIMA, G. F.. Caracterização hidrológica e suscetibilidade de risco à inundação nas bacias do município de Arroio do Padre/RS. Revista Ibero Americana de Ciências Ambientais, v.10, n.1, p.283-296, 2019. DOI: http://doi.org/10.6008/CBPC21796858.2019 .001 .0024
DOI: 10.6008/CBPC2179-6858.2019.001.0024 


\section{INTRODUÇÃO}

Segundo dados do The Internacional Disaster Database (EM-DAT), entre 1995 e 2015, foram registrados 6.457 desastres relacionados ao clima, que causaram 606.000 óbitos e afetaram mais de 4 bilhões de pessoas entre feridos, desabrigados ou que precisaram de ajuda de emergência. De acordo com GuhaSapir et al. (2012), o Brasil é um dos dez países mais afetados por desastres naturais no mundo e o Ministério da Saúde indicou que, de maneira geral, nas estações do verão e outono há uma maior ocorrência de desastres hidrológicos em todas as regiões do país, com destaque para o Sudeste, Sul e Nordeste, enquanto que no inverno e primavera, destaca-se prioritariamente, os registros na região Sul (BRASIL, 2018).

As enxurradas são definidas por Sirangelo (2014) como eventos onde a vazão tem um pico brusco e tempo de duração reduzido e incremento grande na vazão, sendo também chamadas de inundações bruscas. Assim, esses eventos são considerados desastres naturais, os quais são caracterizados como o "resultado de eventos adversos, naturais ou provocado pelo homem, sobre um ecossistema (vulnerável), causando danos humanos, materiais e/ou ambientais e consequentes prejuízos econômicos e sociais" (BRASIL, 2017). No que diz respeito à ocorrência dessas tipologias de desastres no Brasil, entre 1ㅇ de janeiro de 2000 e 31 de julho de 2017, foram registradas 6.164 situações de emergência, reconhecidas pelo Governo Federal, em 2.872 municípios, o que corresponde à 51,5\% da totalidade de municípios do país (BRASIL, 2018).

As questões ligadas à gestão de riscos à desastres, assim como as mudanças climáticas, podem influenciar no grau em que os eventos extremos são sentidos pela população e pelo ecossistema. Dessa forma, a ocorrência e a magnitude desses danos em uma determinada localidade dependerão das vulnerabilidades associadas às condições sociais, econômicas, políticas, ambientais, climáticas, geográficas e sanitárias do território (BRASIL, 2014). Logo, as mudanças climáticas, como fatores desencadeadores de desastres ambientais, precisam ser compreendidas num contexto social e sob os olhares de uma visão sistêmica, de maneira que as consequências advindas de um evento climático extremo, oriundo das mudanças climáticas, poderão variar de acordo com as condições do ambiente no qual impactarem (CARVALHO et al., 2012).

Segundo Tominaga et al. (2009), a chuva tem sido o elemento do clima que provoca as transformações mais rápidas na paisagem, comumente no verão, quando as precipitações ocorrem de forma concentrada, podendo resultar em tragédias, principalmente em áreas de alta concentração urbana. Já para Tasca (2010), a hidrologia traz também a percepção dos fenômenos hidrológicos vivenciados diariamente, o que demonstra também a importância e grandiosidade da água e do convívio integrado com a natureza. Dentro deste contexto, o estudo do ciclo hidrológico e das características hidrológicas dos municípios é extremamente importante. Para isso, utiliza-se a bacia hidrográfica como delimitação da área de estudo, juntamente seus parâmetros morfométricos, possibilitando, assim, a análise da suscetibilidade ao risco de inundação das bacias de interesse.

A integração entre modelos hidrológicos e o Sistema de Informação Geográfica (SIG) vem crescendo significativamente nos últimos anos, principalmente em mapeamentos de áreas de inundação, seja ela em 
áreas urbanas ou rurais, em virtude principalmente do potencial que essa ferramenta apresenta na combinação de dados de tipos e formatos diferentes (CABRAL, 2016). Tais metodologias são capazes de analisar as representações da realidade, por meio de modelos espaciais que consideram os fatores como um sistema integrado, no qual todos os elementos possuem algumas influências nas situações e/ou fenômenos modelados (ALMEIDA, 2007; MOURA, 2007).

No Estado do Rio Grande do Sul, entre 1980 e 2010, foram registradas 1.742 enxurradas, ocorrendo predominantemente nos meses de novembro, dezembro, janeiro e maio (MENEZES et al., 2013). Em específico na região sul do Rio Grande do Sul, o município de Arroio do Padre tornou-se um exemplo emblemático na questão dos desastres naturais, com 6 registros, sendo 2 de seca e estiagem, 3 de enxurrada e 1 de granizo (entre 1991 a 2012) (CEPED, 2013). O município de Arroio do Padre teve a ocorrência de enxurradas por três anos consecutivos, em 28 - 29 de janeiro de 2009; em 15 de novembro de 2010; e em de 09 - 11 de março de 2011, que causaram perdas econômicas e ambientais. Neste contexto, este estudo teve como objetivo descrever as consequências causadas pela ocorrência destes eventos extremos de inundações no município de Arroio do Padre/RS, caracterizar o sistema hidrológico local e analisar a suscetibilidade de ocorrência enxurradas no município.

\section{MATERIAIS E MÉTODOS}

A pesquisa foi desenvolvida no município de Arroio do Padre, o qual está situado da Microrregião de Pelotas, possui uma área de $124,317 \mathrm{~km}^{2}$, tem sua população estimada em 2.730 habitantes, sendo 454 habitantes na área urbana e 2.276 habitantes na área rural (IBGE, 2013). Arroio do Padre é um dos quatro municípios do Brasil que são geograficamente situados 'dentro' de outro município. Neste caso, o município está inserido dentro do município de Pelotas, pois seus limites territoriais são todos com o mesmo, sua localização pode ser observada na Figura 1.

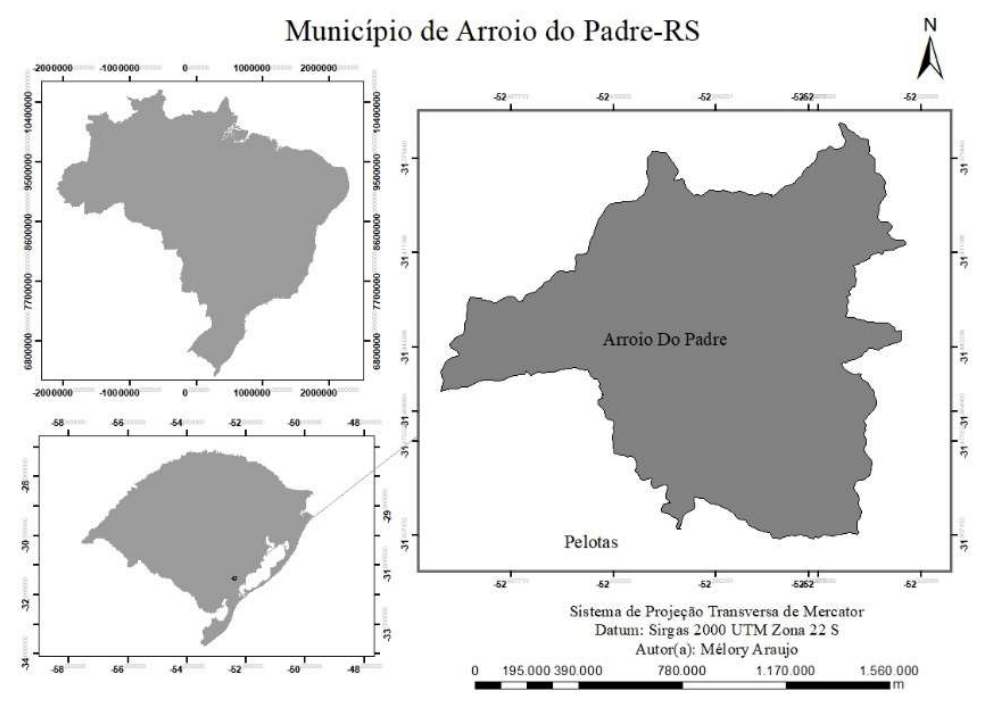

Figura 1: Localização do município de Arroio do Padre.

Inicialmente, foram adquiridos os dados gerais do município, através do site do Instituto Brasileiro de Geografia e Estatística (IBGE), algumas informações foram fornecidas pela Prefeitura Municipal de Arroio 
do Padre e a EMATER/RS (Escritório Municipal de Arroio do Padre), que serviram para caracterizar a área de estudo e para a elaboração de um breve histórico sobre os problemas causados pelas enxurradas no município.

Arroio do Padre está inserido na região hidrográfica da Bacia Mirim-São Gonçalo, ocupa partes das regiões fisiográficas da Serra do Sudeste, Encosta do Sudeste, Litoral e Campanha do Estado do Rio Grande do Sul. O município apresenta dois Arroios de grande influência quanto a ocorrência de enxurradas o Arroio Pimenta e Quilombinho observados na figura 2.

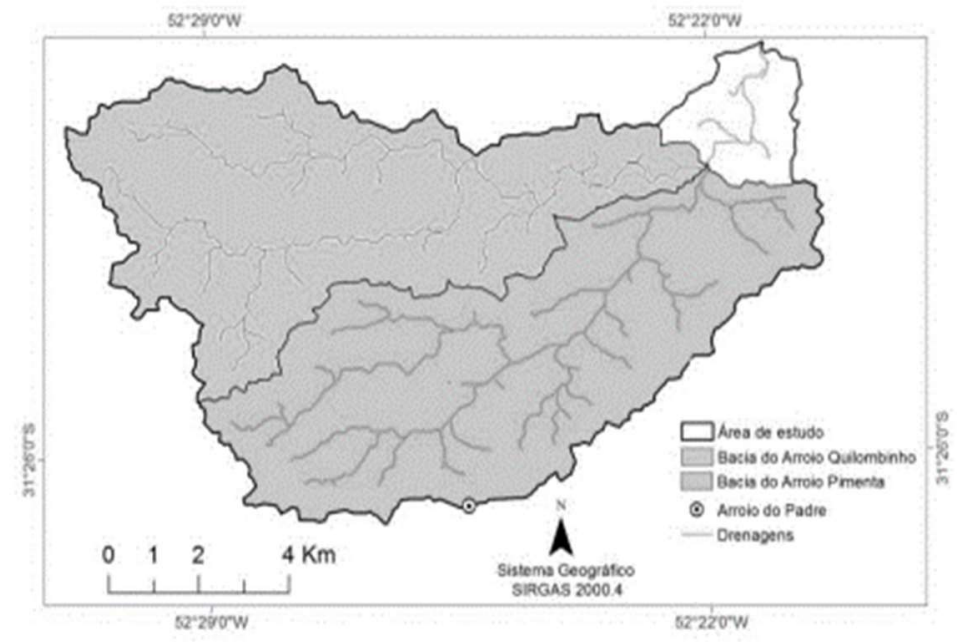

Figura 2: Bacias dos Arroios Pimenta e Quilombinho/RS. Fonte: Wetzel (2015).

Os tipos de solo predominantes na área são os Argissolos Vermelho Amarelo Distróficos e os Neossolos Litólicos Distróficos, esses solos são de baixa fertilidade e apresentam muitas limitações quanto à infiltração, o principal uso do solo é a agricultura e a pecuária leiteira, que são a maior fonte de renda do município. A topografia do município é proeminente, apresenta vários talvegues que drenam o relevo. Segundo o Plano Ambiental Municipal de Arroio do Padre (ARROIO DO PADRE, 2008), nas áreas mais elevadas são de embasamento cristalino, predominam os solos rasos e os afloramentos rochosos e as áreas menos íngremes são de relevo ondulado, o solo apresenta alta suscetibilidade à erosão.

A partir dos dados secundários coletados, para melhor interpretação da suscetibilidade de ocorrência de inundações bruscas/enxurradas, foi empregado o uso de ferramentas de geoprocessamento, para obtenção dos limites das bacias hidrográficas. Para esse processo foram adotados os seguintes passos: a) a aquisição dos dados espaciais; b) a geração do Modelo Digital de Elevação (MDE); c) a eliminação de ruídos; d) a geração de um arquivo de imagem da direção do fluxo; e) a geração de um arquivo de imagem de acúmulo de fluxo; f) a geração de um vetor com um dreno traçado e g) a delimitação das bacias.

Os dados geoespaciais foram adquiridos da Base Vetorial Contínua do Rio Grande do Sul (HASENACK et al., 2010) em escalada 1:50.000, sendo que a análise espacial foi feita através de SIG (Geographic Information System) pelo Software Livre Quantum Gis Wien versão 2.8.1. Posteriormente à aquisição dos dados, os mesmos passaram pelos seguintes procedimentos metodológicos: foram normalizados e associados a um sistema de referência único, WGS 84, e foi definido o sistema de projeção, zona UTM 22 Sul; 
gerou-se o MDE, através de dados altimétricos; os pontos de elevação e as curvas de nível foram moldados com um TIN algoritmo grade de interpolação (rede irregular triangular) para a construção do modelo e o mapa de declividade.

Para a rede de drenagem e das bacias hidrográficas, analisando o MDE, observou-se a presença de pontos espúrios, que são pixel destoantes aos demais, com menores ou maiores altitudes dos arredores, estes picos e depressões interrompem a continuidade da drenagem. Assim, de modo a extrair o comportamento mais semelhante ao da superfície terrestre, corrigiram-se estas imperfeições no processo de deteç̧ão de drenagem. Da mesma forma para o sentido do fluxo, a correção foi feita verificando-se os pixels que possuíam os menores valores de altimetria na vizinhança. Após, foi possível, então, modelar as áreas de acumulo de fluxo da bacia. O acumulo de fluxo é calculado pela direção do fluxo em todas as células que correm para cada célula no raster de saída. A metodologia resultou na rede de drenagem de extração das bacias de Arroio do Padre, os limites das bacias hidrográficas estão associados com as características topográficas do terreno e as tendências de drenagem, por isso as bacias geradas não estão completamente localizadas dentro do limite administrativo urbano.

Para avaliação das características hidrológicas, foram calculadas as características morfométricas a fim de observar se as bacias hidrográficas geradas são sucessíveis a inundações. Os parâmetros considerados foram o Coeficiente de Compacidade (Kc), Índice de conformação (Ic) e o Tempo de concentração (Tc), os quais suas equações são apresentadas a seguir:

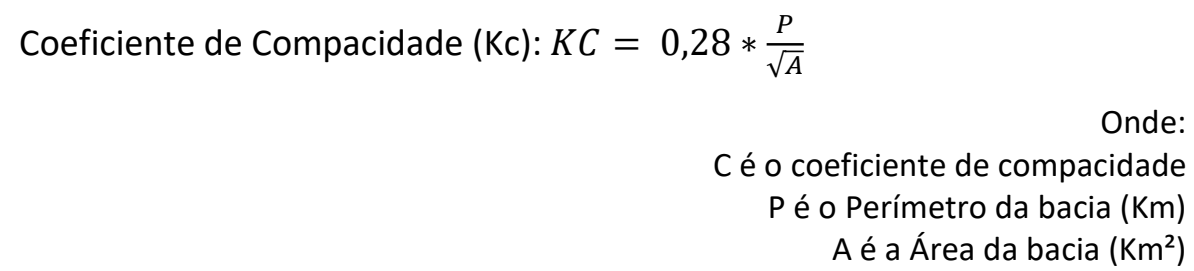

Índice de conformação de cada bacia: $I C=\frac{A}{L^{2} a x}$

IC é o índice de conformação A é a Área da bacia $\left(\mathrm{Km}^{2}\right)$ L2 ax é o comprimento axial da bacia $(\mathrm{Km})$ Tempo de concentração (Tc): Tc $=57 * L^{1,155} * H^{-0,385}$

Onde:

TC é o Tempo de concentração (min) $\mathrm{L}$ é o comprimento do talvegue principal $(\mathrm{Km})$ H é o desnível entre a cabeceira e a seção de controle da bacia $(\mathrm{m})$

Para comparar os resultados da análise hidrológica, foi gerado o mapa de risco de inundação para o munícipio. Utilizando Sistema de Informação Geográfica (SIG) em conjunto com o método de Análise Hierárquica de Pesos (AHP), criado por Saaty (1977), nesta etapa foi realizada uma matriz de comparação, onde os mapas foram cruzados utilizando método de álgebra de mapas utilizando a ferramenta Raster Calculator dentro do software Quantum Gis, obtendo a interação dos dados, para através de um modelo matemático pré-definido elaborar o mapa de risco de inundação para o município. 


\section{RESULTADOS E DISCUSSÃO}

A área urbana de Arroio do Padre apresenta um número reduzido de áreas propensas tanto para inundações quanto para alagamentos. No entanto, a situação não se repete na zona rural, pois os pontos de alagamentos e inundações são frequentes por ação do estrangulamento dos cursos das águas dos arroios, os quais estão presentes principalmente em locais em que existem pontes no município. Segundo Leandro (2013) o tipo climático de uma região é uma informação importante nas atividades de planejamento, já que condiciona toda a dinâmica do ambiente.

A precipitação é um fator importante para a definição climática de uma região, determinante para a sua economia, além de ser o principal mecanismo natural de restabelecimento dos recursos hídricos da superfície terrestre (SIQUEIRA et al., 2018). De acordo com os gestores municipais, em ocasiões de precipitação pluviométrica acima dos $110 \mathrm{~mm}$, em curto espaço de tempo, os arroios que passam pelo município transbordam. Segundo relatos, no ano de 2009, em 31 de janeiro, a ocorrência de uma enxurrada causou erosão nas áreas mais onduladas e alagamento nas lavouras planas. De acordo com a Emater (2010) do município, por consequência deste evento, houve prejuízos principalmente nas lavouras de milho, soja e fumo. Os danos se agravaram também pela falta de energia elétrica, sendo as atividades mais prejudicadas a fumicultura, devido a secagem do fumo que estava em estufas elétricas, e a bovinocultura leiteira.

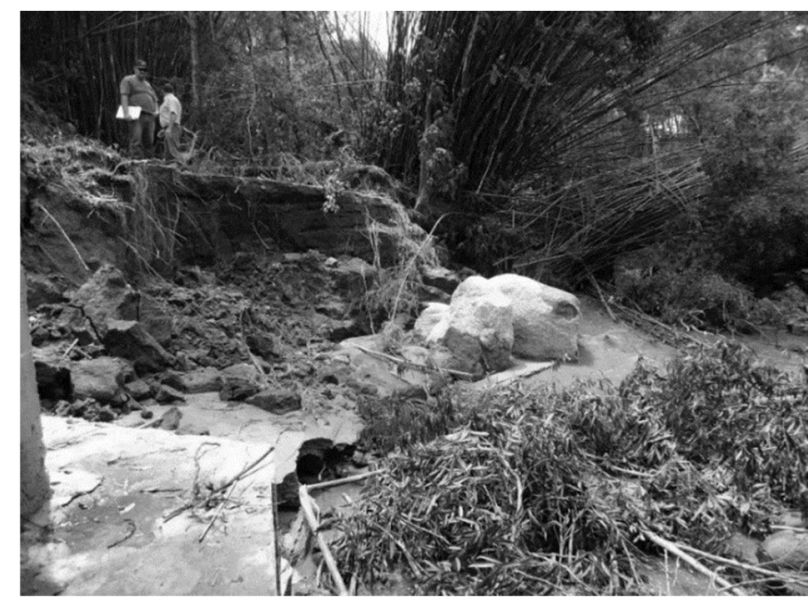

Figura 3: Estrago causado nas margens dos arroios e vegetação ciliar, no evento de 2010. Fonte: Emater

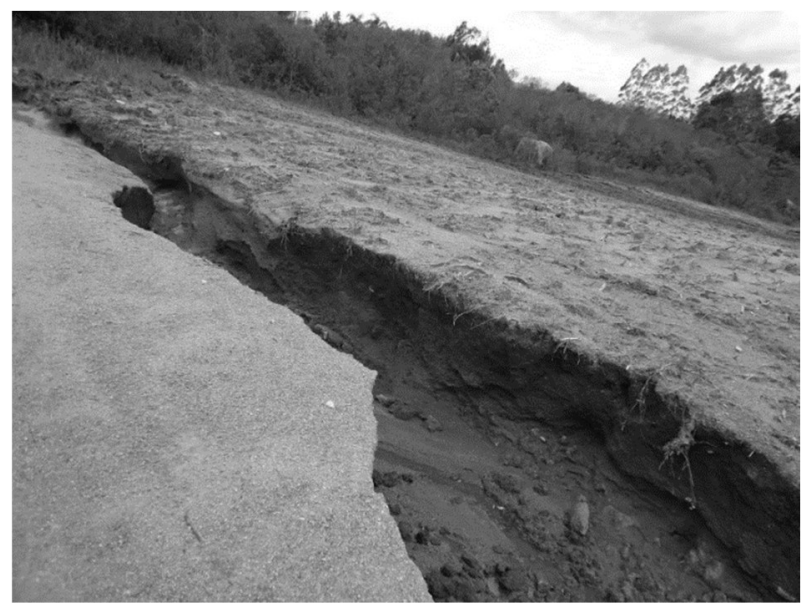

Figura 4: Erosão causada pela enxurrada, no evento de 2010. Fonte: Emater (2010).

(2010).

Em 15 de novembro de 2010, novamente a precipitações atingiram alto índice, chegando a cerca de $320 \mathrm{~mm}$, o que teria ocorrido em um período de aproximadamente 3 horas. Algumas áreas foram atingidas por granizo, que durou em torno de 40 minutos. Segundo a Emater (2010) e a prefeitura do município, o prejuízo foi calculado em valor superior a R\$ 7 milhões, gerando grandes transtornos para a população, pois perdas iniciais foram estimadas em $40 \%$ da área plantada nas lavouras de fumo e $50 \%$ na olericultura, tendo áreas e cultivos com perda total. Além disso, vegetações de mata ciliar foram danificadas em torno de $90 \%$ nas margens dos arroios, sangas e córregos do município, o que teria atingindo poucos metros até perda total de Área de Preservação Permanente (APP), em determinados locais ultrapassando a margem de $100 \mathrm{~m}$ 
calculada a partir do ponto mais alto de alagamento. Alguns dos estragos causados pelo evento de 2010 podem ser observados nas Figuras 3, 4 e 5 e 6.

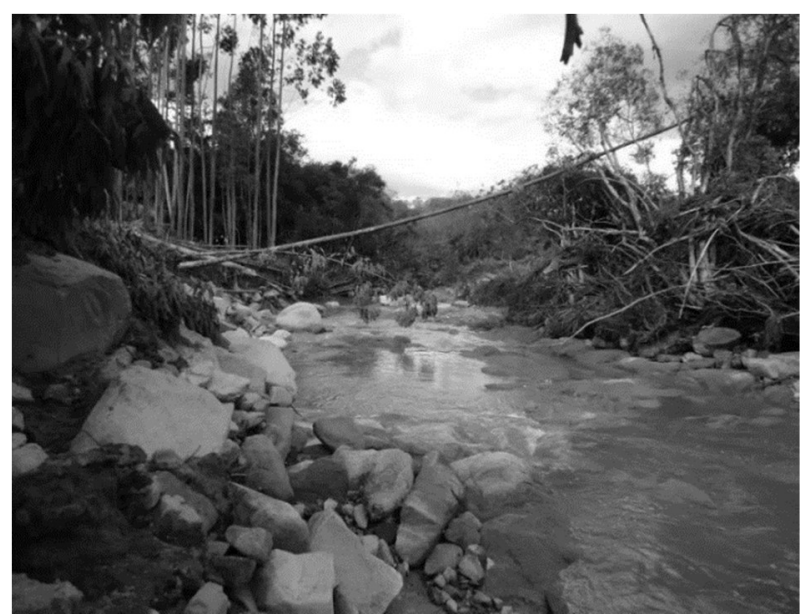

Figura 5: Mudança nas margens dos cursos d'água, no evento de 2010. Fonte: Emater (2010).

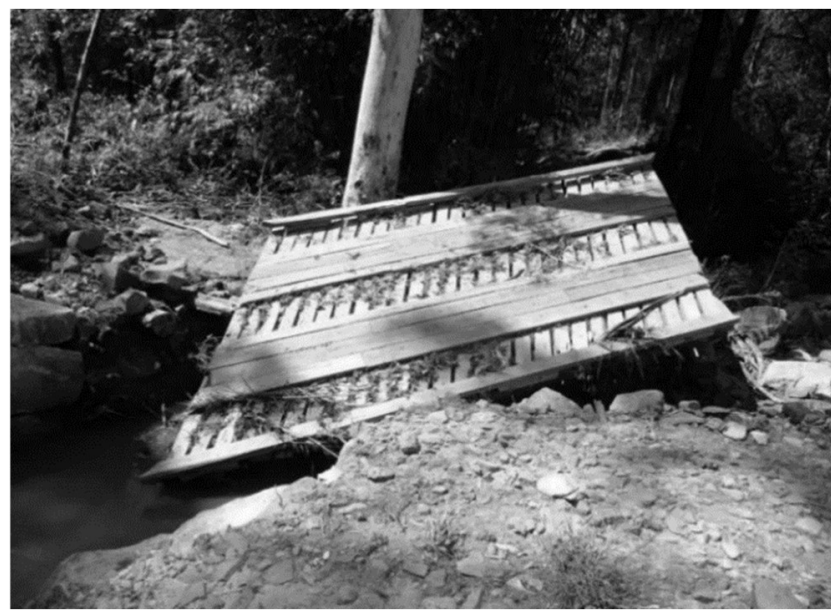

Figura 6: Destruição de pontes ao longo do município, no evento de 2010. Fonte: Emater (2010).

Na semana de 6 a 13 de março de 2011, foram registrados cerca 140 mm de chuva no município, que foi distribuída ao longo da semana. As temperaturas foram entre $23^{\circ} \mathrm{C}$ e $28^{\circ} \mathrm{C}$ com um clima bastante úmido e abafado, normais para a época do ano e com um volume total precipitado, o município decretou situação de emergência. Esta enxurrada provocou estragos nas estradas do interior do município, em pontilhões de acesso a várias comunidades e prejudicou, novamente, os fumicultores e os produtores de leite, que ficaram 12 horas sem luz.

A população, de maneira geral, tente a buscar a ocupação próxima aos rios e arroios com o objetivo de obter os benefícios do sistema hídrico. No entanto, esse fator resulta no estabelecimento de áreas de risco. Segundo Nunes (2016), as mudanças antrópicas combinadas com a distribuição e variabilidade da precipitação levam, em muitos casos, às consequências negativas. Conforme o autor, o aumento progressivo da intervenção humana no meio físico tem gerado a intensificação do grau de risco em diversas regiões, fazendo com que alguns episódios se tornem desastres.

De acordo com Oliveira et al. (2017), irregularidades no regime das precipitações costumam afetar a vida das pessoas e exercer influências nos seus modos de vida. A ocorrência de eventos como enchentes e deslizamentos de massa, por exemplo, estão relacionadas com a maneira como foram construídos e ordenados os espaços e podem ocasionar graves transtornos à vida social, caso a população afetada não esteja preparada para lidar com a ocorrência de eventos extremos.

Esse fator se agrava nas zonas rurais, geralmente pelas condições do local, o que acaba gerando uma degradação no ambiente e intensificando a fragilidade ambiental. Como definido por Leandro (2013), a fragilidade ambiental é a susceptibilidade de um ecossistema em sofrer perturbações, relacionando suas características intrínsecas (tipo de solo, declividade, litologia) e extrínsecas, a exemplo das ações antrópicas e uso e ocupação do solo. Para Franco (2010), a degradação das bacias hidrográficas pode ser caracterizada como qualquer alteração artificial e acelerada, nas características físicas, químicas e biológicas, podendo 
resultar em modificações na geomorfologia, biodiversidade e aspectos quantitativos e qualitativos dos cursos d'água.

Para Marengo (2008), fatores como o processo acelerado de urbanização, o uso e a ocupação do solo e o desmatamento afetam a disponibilidade dos recursos hídricos e os eventos climáticos intensificam todas essas perturbações, ocasionando eventos que geram perdas de vida e danos econômicos, na agricultura, no abastecimento humano de água e na geração de energia hidroelétrica. Os danos causados no município durante os eventos de inundação relatados, corroboram com a pesquisa de Marengo, principalmente nas questões de prejuízos econômicos, abastecimento de água e energia elétrica.

A partir da frequência dos episódios ocorridos no município, é possível fazer uma relação entre o regime hidrológico e as características morfométricas das bacias a fim de associar a probabilidade de eventos extremos. A partir desse diagnóstico, então, pode-se fazer um possível prognóstico com medidas que minimizem prováveis enxurradas e alagamentos futuros. A identificação das áreas atingidas por esses eventos é essencial como subsidio para a adoção e gestão de políticas públicas. Nesse sentido, de acordo com Vieira et al. (2018), a utilização de dados hidro meteorológicos é fundamental para o planejamento e gerenciamento dos recursos hídricos. Além disso, os autores afirmam que a partir dessas informações podem ser estimados índices e indicadores sobre os quais os gestores fundamentam suas tomadas de decisão.

Um estudo realizado por Meurer et al. (2015) apontou que, no município de Arroio do Padre, os principais prejuízos causados pelas enxurradas incidem devido à ocorrência de processos de erosão hídrica, processo desencadeado principalmente pelo grande volume de precipitação em um curto período de tempo ocasionado também movimentos de massa e erosão nos leitos dos arroios. Nos locais de declividade mais acentuada, é possível observar a presença de sulcos e ravinas, algumas delas cortando as lavouras de fumo. Por isso, é de grande importância levar as características do relevo em consideração nos estudos referentes as inundações, pois o relevo influencia diretamente nas características da bacia hidrográfica, determinando o comportamento do escoamento. A combinação dos agentes naturais como a chuva, o vento e o relevo podem intervir nas características da velocidade do escoamento, assim como na transformação da paisagem local pela desagregação das partículas do solo. Assim como, observar outras características do meio físico de um local, como o tipo de solo, de declividade e de cobertura vegetal, é fundamental para interpretar a vulnerabilidade do terreno.

Conhecendo-se a vulnerabilidade, esta pode ser evitada quando algumas medidas são tomadas, como: evitar a total exposição do solo, escolher locais menos declivosos para o corte de terreno (em questões agrícolas), o que evitaria a concentração de águas pluviais, por exemplo. Esse fator aponta a importância para o estudo adequado das características do meio.

Os resultados encontrados indicam o potencial de informações que se pode extrair com o uso de SIG como, por exemplo, o MDE do terreno e as informações obtidas a partir deste assim como considera-lo uma variável independente das demais variáveis topográficas. Na Figura 7, é possível observar o modelo digital de elevação elaborado para o limite municipal, no qual percebe-se que a região possui uma variação 
altimétrica ao redor de 301 metros, apresentando os pontos mais baixos com cerca de 40 metros e os pontos de maior altitude com cerca de 341 metros.

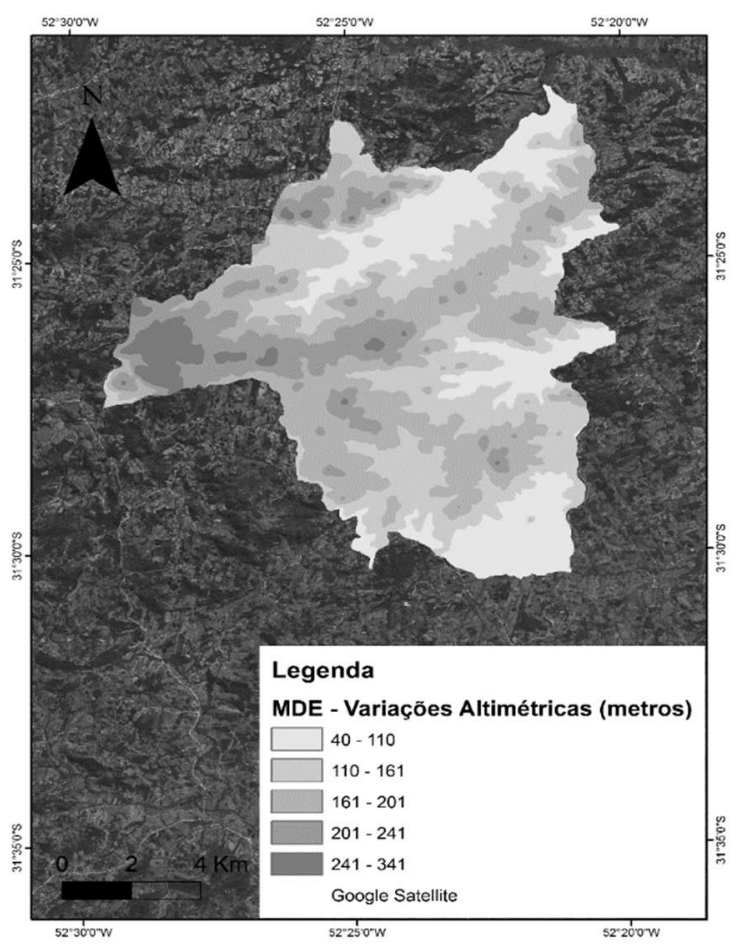

Figura 7: Modelo Digital de Elevação do município de Arroio do Padre/RS.

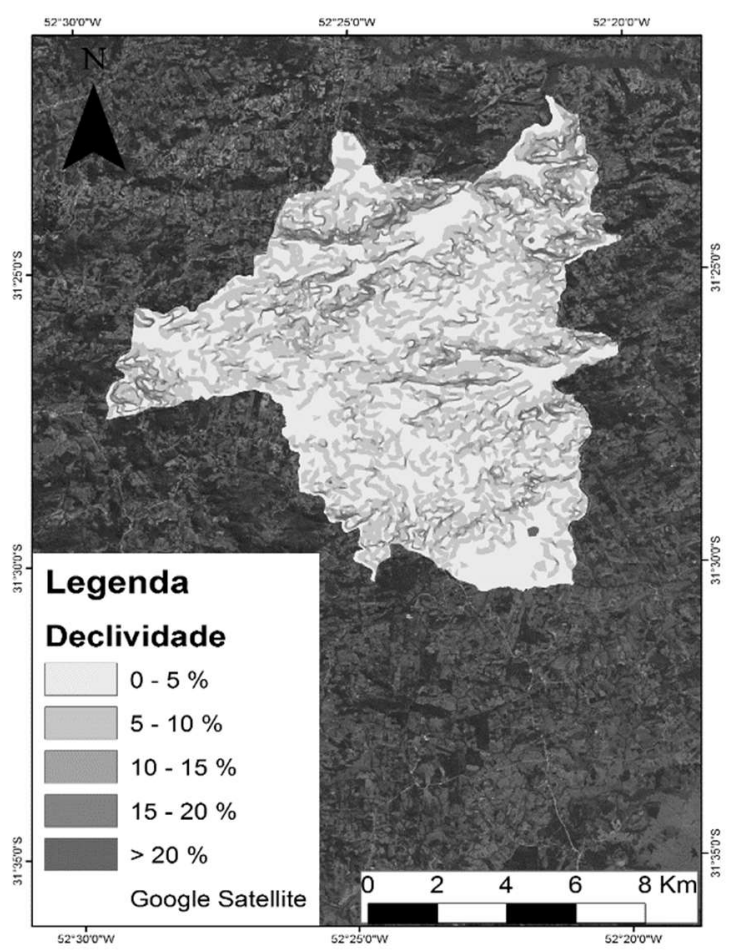

Figura 8: Mapa de declividade do município de Arroio do Padre/RS.

A partir do MDE pode-se obter o mapa de declividade de terreno, visto na Figura 8, onde é possível determinar os pontos mais íngremes do município, o mesmo também pode apresentar as áreas mais suscetíveis a erosão, sendo estas as que apresentam maior declividade. O município de Arroio do Padre apresenta um predomínio de baixas declividades, porém na área rural percebem-se locais com declividade maior que $20 \%$, o que combinado com o tipo de solo da região pode indicar problemas erosivos para a área. Este resultado corrobora com o realizado por Flach et al. (2017) o qual afirma que em Arroio do Padre ocorrem áreas elevadas que formam um conjunto de cristas alongadas, alinhadas preferencialmente nas direções W-E e SW-NE. Ainda para os autores ao longo da crista de menor continuidade lateral, situada na Bacia Hidrográfica do Arroio Pimenta com vertentes bastante íngremes, foram localizadas pelo menos quatro ocorrências de movimentos de massa.

Analisando, inicialmente, a morfometria da área, para o estudo hidrológico, o município de Arroio do Padre foi dividido em sete bacias hidrográficas, como mostra Figura 9, assim foi mensurado a área, perímetro, comprimento do curso d'agua principal, para cada sub bacia hidrográfica. A área da bacia é o elemento básico para o cálculo das outras características físicas. Normalmente é determinada por planimétrica em mapas com escalas razoavelmente grandes (1:50000) e expressa em $\mathrm{km}^{2}$ ou hectares. $\mathrm{Na}$ Tabela 1, são apresentadas as principais informações referentes às bacias hidrográficas delimitadas para Arroio do Padre. 


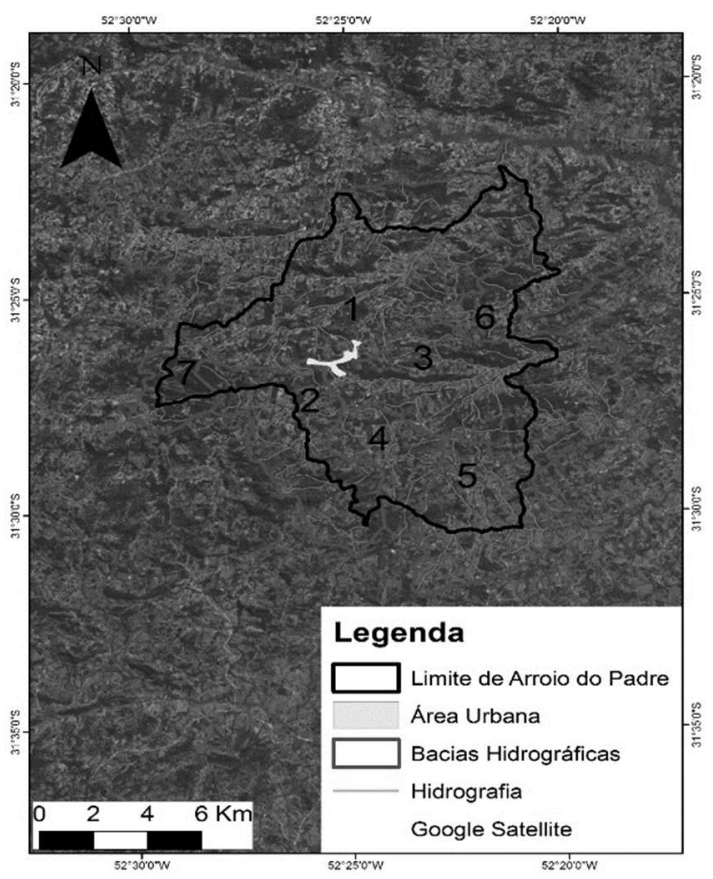

Figura 9: Bacias hidrológicas de Arroio do Padre/RS e rede de drenagem local.

Tabela 1: Informações básicas sobre as bacias hidrográficas de Arroio do Padre/RS.

\begin{tabular}{|l|l|l|l|l|l|}
\hline Bacias & Perímetro $(\mathrm{Km})$ & Área $\left(\mathrm{km}^{2}\right)$ & Desnível $(\mathrm{m})$ & Comp. Axial $(\mathrm{Km})$ & Comp. Rio Principal $(\mathrm{Km})$ \\
\hline 1 & 51,86 & 86,79 & 244 & 14,56 & 17,19 \\
\hline 2 & 28,52 & 27,73 & 130 & 9,78 & 14,01 \\
\hline 3 & 32,88 & 45,15 & 215 & 11,56 & 15,70 \\
\hline 4 & 17,57 & 12,78 & 162 & 5,83 & 7,74 \\
\hline 5 & 21,34 & 23,72 & 160 & 4,69 & 5,42 \\
\hline 6 & 19,41 & 15,39 & 170 & 7,33 & 8,22 \\
\hline 7 & 14,49 & 142 & 4,31 & 6,75 \\
\hline
\end{tabular}

Com base nas informações da Tabela 1, foi realizada a análise morfométrica das bacias de estudo obtendo o Coeficiente de Compacidade (Kc), Índice de Conformação (Ic) e o Tempo de Concentração (Tc), apresentados na Tabela 2.

Tabela 2: Características morfométricas das bacias hidrográficas de Arroio do Padre/RS.

\begin{tabular}{|l|l|l|l|}
\hline Bacia & $\mathrm{Kc}^{1}$ & $\mathrm{Ic}^{2}$ & $\mathrm{Tc}^{3}$ \\
\hline 1 & 1,56 & 21,03 & 151,5 \\
\hline 2 & 1,52 & 12,22 & 121,9 \\
\hline 3 & 1,37 & 17,26 & 121,8 \\
\hline 4 & 1,38 & 9,14 & 61,5 \\
\hline 5 & 1,23 & 13,96 & 48,22 \\
\hline 6 & 1,39 & 9,96 & 78,76 \\
\hline 7 & 1,36 & 7,70 & 45,73 \\
\hline
\end{tabular}

${ }^{1} \mathrm{Kc}$ : Coeficiente de Compacidade

${ }^{2}$ Ic: Índice de Conformação

${ }^{3} \mathrm{Tc}$ : Tempo de Concentração

Dentre as características das bacias hidrográficas, o Coeficiente de Compacidade é número adimensional calculado que varia com a forma da bacia independente do seu tamanho, assim quanto mais irregular ela for, maior será o coeficiente de compacidade, ou seja, quanto mais próxima da unidade, mais circular será a bacia e, portanto, mais sujeita à ocorrência de cheias (VILLELA et al., 1975). Os mesmos autores indicam que se os resultados encontrados forem em uma faixa de 1,00 a 1,25 existe alta propensão a grandes cheias; de 1,25 a 1,50 esta tendência é mediana; e maiores que 1,50 a bacia não é propensa a grandes cheias. 
A análise obtida pelo Kc (Tabela 2) indica que as Bacias 1 e 2 possuem uma tendência de não apresentarem problemas de cheias pela sua forma. No entanto, cabe ressaltar que a Bacia 1 é composta pelos Arroios Pimenta e Quilombinho, os quais são os dois maiores contribuintes hidrológicos da região e apresentam histórico de enxurradas. Observa-se também que a Bacia 5 apresenta um Kc de 1,23, valor que representa alta propensão à grandes cheias. Já as demais bacias apresentam vulnerabilidade mediana para cheias, no entanto, na realidade é observado menor número de eventos de enxurradas nessas bacias quando comparadas com a Bacia 1, que não apresenta tendência de cheias. Por conta disso, é importante realizar a análise mormofétrica das bacias hidrográficas sempre associando os valores encontrados com a realidade local e também à outras ferramentas como os mapas temáticos, por exemplo.

Em uma caracterização morfométrica da sub-bacia do rio Poxim-Açu em Sergipe, Brasil, os autores verificaram um Kc de 1,76, demonstrando que a sub-bacia em estudo tinha pouca tendência a picos de enchentes, o que se justificava pelo fato de esta bacia ter formato alongado (ROCHA et al., 2014). Devido a esse fato, podemos considerar que, tanto no caso da Bacia 1 quando da Bacia 2, o Kc estaria no limite em relação a tendência média e a tendência de não propensão às cheias, o que não ocorre na pesquisa de Rocha et al. (2014), em que o Kc está bem acima de 1,50.

Silva Jr. et al. (2011) também utilizaram índices morfométricos para caracterizar o potencial hidrológico da bacia hidrográfica do Rio Mimoso e verificaram que a bacia se mostrava pouco susceptível a cheias em condições normais de precipitação pelo fato de o Kc apresentar-se afastado da unidade $(1,63)$ e, quanto ao seu Índice de Conformação, exibiu um valor baixo $(0,214)$, indicando que a bacia não possuía forma circular, mas, sim, aproximadamente alongada.

O Índice de Conformação (Ic) mostra o quanto a forma da bacia hidrográfica se aproxima da forma circular e ele representa a relação entre a área da bacia e um quadrado de lado igual ao comprimento axial da bacia. Quando o Ic é maior que 0,51, mais a bacia se aproxima da forma circular e este índice, portanto, também expressa a capacidade da bacia em gerar enchentes. Quando o Kc for menor que 1, menor a propensão a enchentes na bacia e quando maior que 1 , mais propensa a picos de cheia é a bacia, pois a mesma fica cada vez mais próxima de um quadrado e com maior concentração de fluxo. No caso de uma bacia estreita e longa, a possibilidade de ocorrência de chuvas intensas cobrindo, ao mesmo tempo, toda sua extensão, é menor do que em bacias largas e curtas.

Os valores encontrados para os Ic das bacias demonstram que a Bacia 1 e a Bacia 2 apresentam um índice elevado (Tabela 2), o que indica a grande chance de ocorrência de cheias. Esse índice confirma as ocorrências de eventos extremos de enxurradas nos Arroios Pimenta e Quilombinho. As Bacias 3, 4, 5, 6 e 7 também apresentaram um Ic variando de 7,70 a 17,26 mostrando-se propensas a picos de cheias (Tabela). Assim, analisando o Ic, todas as bacias hidrográficas que englobam o município de Arroio do Padre apresentam tendência às cheias.

Em relação ao Tempo de concentração (Tc), este é definido como sendo o tempo, a partir do início da precipitação, necessário para que toda a bacia contribua com a vazão na seção de controle. Para as bacias 
de Arroio do Padre, a partir da Equação 3, foram obtidos os Tc (Tabela 2), sendo que nenhuma das bacias superava a área de 1000 ha.

Observa-se que a Bacia 5 e a Bacia 7 (Tabela 2) apresentam um Tc inferior a uma hora, o que significa que com grande volume de precipitação em pouco tempo sobre elas pode gerar um aumento em seu nível, ocasionando eventos de enxurradas. Já a Bacia 1, por ser a maior bacia do município, apresenta o maior Tc. No entanto, é preciso levar em consideração também outros elementos como o relevo, a vegetação, o uso e a ocupação do solo nessa região, fatores de grande importância que podem influenciar na redução do Tc das bacias. Rezende et al. (2015) corroboram com esta afirmação quando indicam que, além da análise do Tc das bacias, a elaboração de mapas de uso do solo e, consequentemente, a identificação do grau de impermeabilização das mesmas é capaz de apontar processos que podem afetar consideravelmente no aumento de eventos de inundações.

Para Damasco et al. (2014) um sistema de gerenciamento de áreas inundáveis dentro de uma bacia hidrográfica implica em conhecer o problema através do mapeamento dos riscos, hierarquizados em seus diferentes níveis de potencialidade perigosa, para poder planejar e estabelecer medidas preventivas, corretivas e administrativas para controlar o uso e ocupação dessas áreas. Neste contexto, o produto gerado pelo método de álgebra dos mapas, indica a importância desse levantamento de dados, pois a maior parte das bacias hidrográficas presentes no município de Arroio do Padre apresentam alto risco de ocorrência de inundação (Figura 10). Esse método levou em consideração elementos como uso e ocupação do solo, tipo do solo e altitude do terreno e não considerou fatores hidrológicos, porém o resultado concorda com os resultados obtidos pelos índices anteriormente citados, principalmente com o lc, pois a Bacia 1, no mapa de risco de inundação, é a que apresenta uma área com um altíssimo risco de ocorrência de inundação, como pode ser observado na Figura 10.

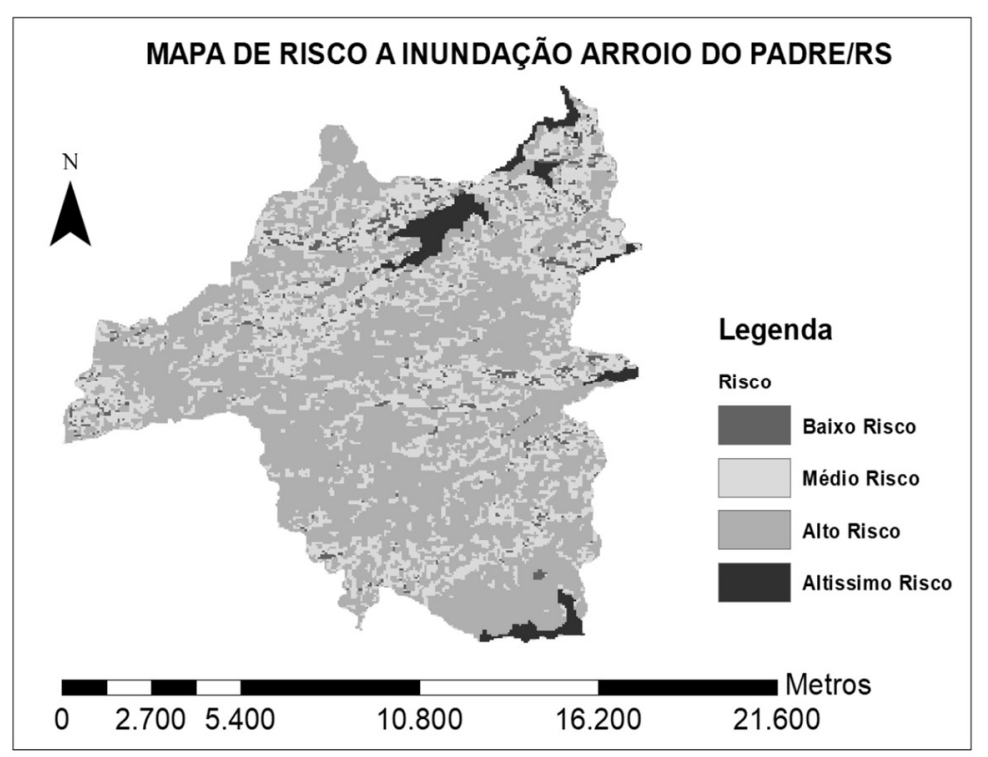

Figura 10: Mapa de risco à inundação do município de Arroio do Padre/RS. 


\section{CONCLUSÕES}

Através da análise das bacias hidrográficas do município de Arroio do Padre/RS e a partir das suas características morfométricas, conclui-se que o município tem grande tendência a ter inundações bruscas/enxurradas, o que corrobora com os eventos que ocorrem da região, sendo alguns relatados neste estudo.

O uso das ferramentas de SIG se mostram promissoras para o estudo das bacias hidrográficas a medida que permitem a análise integrada de diversos elementos, geração de mapas e modelos digitais além de permitirem a comparação de cenários. A incorporação desses instrumentos na gestão de bacias hidrográficas tem potencial para otimizar os processos de análise e tomada de decisão sobre as questões socioambientais.

Ainda, ressalta-se a importância da realização de diagnósticos como o realizado neste estudo para que sirvam de base para a gestão e políticas públicas municipais voltadas para a prevenção de eventos de desastres naturais e proteção de áreas de vulnerabilidade socioambiental. No caso de Arroio do Padre, com base no estudo, fica evidente que o município deve se preparar para eventuais enxurradas e se prevenir através de um manejo de suas bacias hidrográficas, aliado ao adequado uso e ocupação do solo.

AGRADECIMENTOS: Ao Núcleo de Ensino, Pesquisa e Extensão em Saneamento Ambiental (NPSA), à Prefeitura Municipal e ao escritório da EMATER de Arroio do Padre/RS.

\section{REFERÊNCIAS}

ALMEIDA, C. M.. O diálogo entre as dimensões real e virtual urbano. In: ALMEIDA, M. C.; CÂMARA, G.; MONTEIRO, A. M. V.. Geoinformação em urbanismo: cidade real $x$ cidade virtual. Oficina de Texto, 2007.

ARROIO DO PADRE. Plano Ambiental Municipal de Arroio do Padre. 2008.

BRASIL. Ministério da Integração Nacional. Secretaria Nacional de Proteção e Defesa Civil. Centro Nacional de Gerenciamento de Riscos e Desastres. Anuário brasileiro de desastres naturais: 2013. Brasília: CENAD, 2014.

BRASIL. Ministério da Saúde. Boletim Epidemiológico. Brasília: Secretaria de Vigilância em Saúde, 2018.

BRASIL. Ministério da Integração Nacional. Critérios para a Decretação Situação de Emergência ou Estado de Calamidade Pública. Brasília: Secretaria Nacional de Proteção e Defesa Civil, 2017.

CABRAL, F. G.. Uma proposta de um modelo periódico multivariado autorregressivo multiplicativo para geração de cenários de afluência aplicável ao modelo de planejamento do setor elétrico brasileiro. Dissertação (Mestrado) - Universidade Federal do Rio de Janeiro, 2016.

CARVALHO, D. W.; DAMACENA, F. D. L.. A intensificação dos desastres naturais, as mudanças climáticas e o papel do Direito Ambiental. Brasília, 2012.
CEPED. Centro Universitário de Estudos e Pesquisas sobre Desastres. Atlas Brasileiro de Desastres Naturais: 1991 a 2012 - Rio Grande do Sul. Florianópolis: CEPED UFSC, 2013.

DAMASCO, F. S.; FURTADO, T. V.; GONÇALVES, A. J. B.. Risco de inundação em áreas rurais: bacia do rio Luís Alves (SC). Geografia Ensino \& Pesquisa, v.18, n.1, 2014. DOI: http://doi.org/10.5902/223649948902

EMATER. Escritório Municipal de Arroio do Padre. Laudo preliminar de prejuízos econômicos na atividade agropecuária do município em decorrência do excesso de chuvas. 2010.

FLACH, C. W.; MEURER, M.. Os desafios da Geografia física na fronteira do conhecimento: Inventário de movimentos de massa em Arroio do Padre/RS. Campinas: Unicamp, 2017.

GUHA-SAPIR, D.; VOS, F.; BELOW, R.; PONSERRE, S.. Annual Disaster Statistical Review 2011: The numbers and trends. Centre for Research on the Epidemiology of Disasters (CRED) Institute of Health and Society (IRSS). Brussels: Université Catholique de Louvain, 2012.

HASENACK, H.; WEBER, E.. Base cartográfica vetorial contínua do Rio Grande do Sul: escala 1:50.000. Porto Alegre: UFRGS, 2010. 
IBGE. Instituto Brasileiro de Geografia e Estatística. Base de Dados: Cidades. 2013.

LEANDRO, D.. Modelagem de fragilidade ambiental usando índices baseados em dados especiais e com suporte de sistema especialista. Tese (Doutorado em Ciências Geodésicas) - Universidade Federal do Paraná, Curitiba, 2013.

MARENGO, J. A.. Mudanças climáticas globais e seus efeitos sobre a biodiversidade: caracterização do clima atual e definição das alterações climáticas para o território brasileiro ao longo do século XXI. v.26. Brasília: MMA, 2006.

MENEZES, D. J.; SCCOTI, A. A. V.. Inventário de registro de inundações no Estado do Rio Grande do Sul entre 1980 e 2010. In: ROBAINA, L. E. D.; TRENTIN, R.. Desastres Naturais no Rio Grande do Sul. Santa Maria: UFSM, 2013.

MEURER, M.; WERNER, F. C.. A Geomorfologia do município de Arroio do Padre/RS e as suas relações com as alterações geomorfológicas da enxurrada de 15 de novembro de 2010 . Ciência e Natura, v.37, n.3, p.311-328, 2015. DOI: http://dx.doi.org/105902/2179460X

MOURA, A. C. M.. Reflexões metodológicas como subsídio para estudos ambientais baseados em Análise de Multicritérios. In: SIMPÓSIO BRASILEIRO DE SENSORIAMENTO REMOTO, 13. Anais. Florianópolis, 2007.

NUNES, L. H.. Compreensões e ações frente aos padrões espaciais e temporais de riscos e desastres. Territorium, n.16, p.179-189, 2016.

OLIVEIRA, D.; FERREIRA, C. C. M.. Gênese e ritmo da pluviosidade na Bacia do Rio Preto MG/RJ: proposta metodológica para a representação cartográfica. Revista Brasileira de Climatologia, v.21, 2017. DOI: http://dx.doi.org/10.5380/abclima.v21i0

REZENDE, G. B. M.; ARAÚJO, S. M. S.. Análise da taxa de impermeabilização e tempo de concentração nas sub-bacias da área urbana de Barra do Garças/MT, Pontal do Araguaia/MT e Aragarças/GO. Revista Verde, v.10, n.5, p.2737, 2015. DOI: http://doi.org/10.18378/rvads.v10i5.3727

ROCHA, R. M.; LUCAS, A. A. T.; ALMEIRA, C. A. P. A.; MENEZES NETO, E. L.; NETTO, A. O. A.. Caracterização morfométrica da sub-bacia do rio Poxim-Açu, Sergipe, Brasil.
Revista Ambiente e Água, v.9, n.2, p.276-287, 2014. DOI: http://dx.doi.org/10.4136/ambi-agua.1289

SAATY, T. L.. A scaling method for priorities in hierarchical structures. Journal of Mathematical Psychology, v.15, n.3, p.234-281, 1977. DOI: http://doi.org/10.1016/00222496(77)90033-5

SILVA JUNIOR, V. P.; MONTENEGRO, A. A. A.; SILVA, T. P. N.; GUERRA, S. M. S.; SANTOS, E. S.. Produção de água e sedimentos em bacia representativa do semiárido pernambucano. Revista Brasileira de Engenharia Agrícola e Ambiental, v.15, n.10, p.1073-1081, 2011. DOI: http://dx.doi.org/10.1590/S1415-43662011001000012

SIRANGELO, F. R.. Relação entre a ocorrência de inundações e enxurradas e os índices morfométricos das sub-bacias hidrográficas da região hidrográficas do Guaíba - Rio Grande do Sul, Brasil. Porto Alegre: UFRGS, 2014.

SIQUEIRA, B.; NERY, J.; MARTINS, G.. Variabilidade sazonal da precipitação na bacia do paraná em território brasileiro. Revista Brasileira de Climatologia, v.23, 2018. DOI: http://dx.doi.org/10.5380/abclima.v23i0.59508

TASCA, A. F.; GOERL, R. F.; KOBIYAMA, M.. Prevenção de desastres naturais através da educação ambiental com ênfase na ciência hidrológica. In: Simpósio de Engenharia Sanitária e Meio Ambiente da Zona da Mata Mineira, 1. Anais. 2010.

TOMINAGA, L. K.; SANTORO, J.; AMARAL, R.. Desastres naturais: conhecer para prevenir. São Paulo: Instituto Geológico, 2009.

VIEIRA, S. A.; OSORIO, D. M. M.; QUEVEDO, D. M.; ADAM, K. N.; PEREIRA, M. A. F.. Metodologia de imputação de dados hidrometeorológicos para análise de séries históricas -Bacia do Rio dos Sinos, RS, Brasil. Revista Brasileira de Climatologia, v.23, 2018. DOI: http://dx.doi.org/10.5380/abclima.v23i0.56219

VILLELA, S. M.; MATTOS, A.. Hidrologia aplicada. São Paulo: Mc Graw Hill, 1975.

WETZEL, R. S.; STRIEDER, A. J.. Mapeamento geológicogeotécnico e riscos naturais nas bacias dos Arroios Pimenta e Quilombinho, Município de Arroio do Padre/RS. In: CONGRESSO BRASILEIRO DE GEOLOGIA DE ENGENHARIA E AMBIENTAL, 15. Anais, 2015.

A CBPC - Companhia Brasileira de Produção Científica (CNPJ: 11.221.422/0001-03) detém os direitos materiais desta publicação. Os direitos referem-se à publicação do trabalho em qualquer parte do mundo, incluindo os direitos às renovações, expansões e disseminações da contribuição, bem como outros direitos subsidiários. Todos os trabalhos publicados eletronicamente poderão posteriormente ser publicados em coletâneas impressas sob coordenação da Sustenere Publishing, da Companhia Brasileira de Produção Científica e seus parceiros autorizados. Os (as) autores (as) preservam os direitos autorais, mas não têm permissão para a publicação da contribuição em outro meio, impresso ou digital, em português ou em tradução. 